\title{
ПРОБЛЕМА ПРЕОБРАЗОВАНИЯ И ЛИКВИДАЦИИ ЭКОНОМИЧЕСКОГО ПРАВОСУДИЯ В РОССИИ В ПЕРИОДИЧЕСКОЙ ПЕЧАТИ ВТОРОЙ ПОЛОВИНЫ ХІХ ВЕКА
}

\section{THE PROBLEM OF TRANSFORMATION AND ELIMINATION OF ECONOMIC JUSTICE IN RUSSIA IN THE PERIODIC PRINT OF THE SECOND HALF OF THE XIX CENTURY}

\section{Olshanskaya}

Summary: The article examines the problem of the transformation and liquidation of commercial courts in Russia after the judicial reform, resolving disputes in the field of entrepreneurship. The author researched, analyzed and compared the opinions of lawyers and representatives of the merchant class. Conclusions are made about the mechanisms of modernization of economic justice in Russia in the second half of the 19th century, about the reasons for the partial liquidation of courts, about the adequate need for their functioning for the development of the Russian economy.

Keywords: commercial court, polemics, transformation of courts, liquidation of economic justice.

\author{
Ольшанская Людмила Владимировна \\ К.и.н., Российский университет транспорта РУТ (МИИТ), \\ Москва \\ olshanskaya.miit@mail.ru
}

Аннотация: В статье рассматривается проблема преобразования и ликвидации коммерческих судов в России после Судебной реформы, разрешающих споры в сфере предпринимательства. Автором исследованы, проанализированы и сопоставлены мнения юристов и представителей купечества. Сделаны выводы о механизмах модернизации экономического правосудия в России во второй половине XIX века, о причинах частичной ликвидации судов, 06 адекватной потребности их функционирования для развития российской экономики.

Ключевые слова: коммерческий суд, полемика, преобразование судов, ликвидация экономического правосудия.

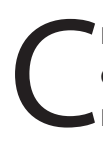

начала XIX века в Российской империи успешно функционировали коммерческие суды, разрешающие споры в сфере предпринимательства, тем самым способствуя динамично развивающимся экономическим отношениям в стране. После открытия первого коммерческого суда в Одессе в 1808 году [6, с.115], подобные суды стали учреждаться в крупнейших торговых центрах России: в Таганроге [7, с. 125], Феодосии [9, с. 363], Керчи [8, с. 130], Архангельске [10, с. 25], а позже в Санкт-Петербурге, Москве [11, с. 268] и других городах.

В ходе Судебной реформы, упразднившей специальные суды, дальнейшая судьба экономического правосудия, в частности коммерческих судов, осталась нерешенной и вопрос об их полной ликвидации или преобразовании был выделен из общих работ по Судебной реформе. Высказывались мнения, что коммерческие суды следует трансформировать и подчинить судебным палатам наравне с судами окружными [3]. Был создан ряд комиссий, заключения которых о дальнейшей судьбе коммерческих судов были противоположны и высказывались мнения как о трансформации торговых судов, так и о полной их ликвидации [4].

В связи с этим в 70-80 гг. XIX века в периодической печати поднялась жаркая полемика как об устройстве коммерческих судов, так и об их дальнейшем существовании.

Дискуссия о самостоятельном торговом судопроизводстве велась, в основном, на страницах юридических журналов, о чем «распространился слух, - писал русский юрист Садовский В.С, - проникший и в печать, будто существует предположение преобразовать коммерческие суды, чтобы подчинить их судебным палатам, к производству по торговым делам применить порядок сокращенного производства, уничтожить штрафы за неправые споры и иски, штаты коммерческих судов сравнять со штатами судов окружных, некоторые коммерческие суды совсем закрыть и т.д. Позже, когда было можно уже ожидать осуществления этих предположений, появились слухи, что будто бы назрел новый проект и на этот раз более решительный: совершенно упразднить коммерческие суды или, по примеру Германии, сохранить их в виде торговых отделений окружных судов» $[12$, с. 1].

Вопрос о коммерческих судах, в смысле их совершенного упразднения или только преобразования, возникал неоднократно и в судебно-административных сферах, и в периодике, и в обществе, но ни к какому серьезному 
практическому результату не привел, так как составленный комиссией под председательством Э.В. Фриша проект Устава торгового судопроизводства [13], хотя и отличался крупными и несомненными достоинствами, однако, оказался неосуществленным и коммерческие суды продолжали существовать, не претерпев почти никаких изменений в своей организации. Толчком к возникновению вопроса о коммерческих судах послужило введение судебных установлений, организованных по началам Судебных уставов Императора Александра II.

При действии дореформенного порядка судопроизводства не было основания к возбуждению вопроса об упразднении или преобразовании коммерческих судов ввиду явного превосходства механизма их производства перед порядком общих судов того времени.

Но с введением новых судебных установлений положение несколько изменилось. Старые суды оставили в себе недобрую память, новые же, призванные заменить их, «в силу одного этого обстоятельства, сразу завоевали всеобщее расположение и возбудили самые сангвинические ожидания. А так как многие взглянули на коммерческие суды, как на обломок, случайно уцелевший от общего крушения дореформенных судов, то и неудивительно, что явилась соблазнительная мысль: подчинить рассмотрение торговых дел общим судебным установлениям, а торговую юрисдикцию упразднить» $[12$, с. 2].

К такому выводу пришла учрежденная для работ по преобразованию судебной части Комиссия, состоявшаяся под председательством действительного тайного советника, статс-секретаря В.П. Буткова. Аналогичной точки зрения придерживались многие окружные суды и судебные палаты в замечаниях на вышеозначенный Проект устава торгового судопроизводства.

По данному вопросу однозначна точка зрения В.С. Садовского, который пишет, что коммерческие суды не допустимо смешивать с другими дореформенными судами в силу того, что основу Устава торгового производства положены устность и гласность, то есть те же самые начала, на которых «зиждется процесс новых судебных ставов и которые были совершенно неизвестны старым судам». В этом отношении Судебные уставы, сравнительно с Уставом торгового судопроизводства, сказали мало нового, хотя указанные процессуальные начала в судебных уставах «развиты подробнее и систематичнее» [12, C. 2].

Несомненно, можно возразить, что указываемые различия и сходства носили чисто формальный характер и что по духу коммерческие и другие дореформенные суды являлись совершенно родственными, и это последнее обстоятельство и могло быть главной причиной упразднительных стремлений по отношению к коммерческим судам. Нельзя не заметить, что хотя прошлое не- которых коммерческих судов и не безукоризненно, но это относилось к тому времени, когда судейская недобросовестность представляла чуть ли не общее явление и потому неудивительно, что коммерческие суды не составляли исключения из общего правила. Но вследствие различных причин общественные и «судейские нравы улучшились», и коммерческие суды не составляли исключения из общего правила. Таким образом, если и было время, когда предубеждение против коммерческих судов имело некоторое основание, то оно прошло, да и основание это легко могло быть устранено частными преобразованиями в организации коммерческих судов и переменами в их личном составе; устранить же необходимость частных мероприятий совершенным упразднением торговой юрисдикции, значит «разрубить узел, а не распутать его, как того требуют интересы нашей действительности» $[12$, с. 1]. Что же касается достижения основных целей правосудия то, если бы торговые дела рассматривались общими судебными установлениями, даже в порядке сокращенного судопроизводства, то на этот вопрос можно ответить только отрицательно. Оспариваемое В.С. Садовским мнение обыкновенно мотивировалось как полезностью единообразия судебного устройства, так и превосходством нового порядка судопроизводства.

Несомненно, что единообразие судебных установлений желательно, так как оно, устраняя вопрос о подсудности по роду дел и устанавливая один общий порядок судопроизводства, упрощал задачу и положение тяжущихся. Не следует упускать из виду, что организация судебных установлений должна была отличаться известной схоластичностью и применимостью к потребностям практический жизни и что потребности эти, по сложности и своей своеобразности, не всегда могли быть удовлетворены, если судебная организация страдала излишней прямолинейностью.

Такую же точку зрения высказывал на страницах «Журнала гражданского и торгового права» специалист в области судопроизводства Н. Депп: «Если из массы имущественных сделок выделяется по своим особым свойствам целая группа сделок и если среда, в которой возникают эти сделки, отличается своеобразностью, доступной пониманию только тех лиц, которые вращаются в этой среде, то это необходимо вызовет возникновение особой подсудности, так как для оценки понимания могущих возникнуть из подобных сделок отношений, необходимы и особые приемы производства и особый состав судей. Следует заметить, что против обособления подсудности только тогда следует ратовать, если это обособление создается искусственно» $[1$, с. 5$]$.

То есть, если такое положение вещей вызывается самой жизнью и особыми свойствами целой группы однородных сделок, то законодатель обязан считаться с подобного рода заявлением и «не закрывать глаз, чтобы не 
видеть его» [12, с. 6].

Что касается другого аргумента - превосходства нового порядка судопроизводства, то нельзя не признать, что когда-то господствовавшее мнение о безусловных его достоинствах страдало преувеличением, что отчасти доказывается целым рядом новейших узаконений $[12$, с. 4] (в частности, «Об изменении порядка заочного разбирательства по гражданским делам и об обеспечении доказательств в местностях, где введено Положение о Земских Участковых начальниках»), предпринятых с целью поправок и дополнений и даже полной отмены общего порядка судопроизводства по некоторым рода делам. Нельзя сказать, что новый порядок был полностью отрицателен, но до известной степени разделялось мнение составителей проекта Устава торгового судопроизводства, что «новые суды вполне хороши для дел, отнесенных к их ведомству» [12, с. 4], но замечалось, что они недостаточно приспособлены к особенностям торговых дел.

Противоположную точку зрения высказывал на страницах «Журнала Министерства Юстиции» выдающийся русский юрист, цивилист, профессор Казанского и Московского университетов Г.Ф. Шершеневич, который писал, что распространению коммерческой юрисдикции способствовало жалкое положение дореформенных судов, в которых дела лежали годами, а ускорение производства зависело от величины взятки, в которых личных состав не обеспечивал ни юридической опытности, ни добросовестности. При такой организации общих судов существование специальных, коммерческих судов представлялось несомненным благоденствием для купечества, которому могли завидовать другие классы общества $[14$, с. 40$]$.

Но, по мнению Г.Ф. Шершеневича, Судебная реформа «такую ситуацию сделала неактуальной, поставив сразу дело правосудия на такую высоту, которая могла казаться предшествующему поколению утопией» [14, с. 43]. После Судебной реформы состав суда, за редким исключением, изменился: он стал состоять только из тех лиц, которые получили юридическое образование. «Коммерческий суд во второй половине XIX века находился под полным контролем гласности и канцелярские тайны уже не имели места, выше всяких похвал была добросовестность судей, которые не допускали никакой двусмысленности, не давая простора намекам даже со стороны противников судебной реформы. Производство дел ускорилось и в гражданских судах, оставив позади себя коммерческое судопроизводство» [14, с. 41].

То обстоятельство, что купечество являлось ярым сторонником коммерческих судов, замечает Шершеневич, еще не говорит в пользу целесообразности и желательности их. Правильное построение уголовного или гражданского процесса могло быть произведено только трудом образованных и опытных юристов. Желает ли само купечество коммерческих судов - вопрос открытый, потому что до сих пор поданные мнения исходят не от всего этого сословия, а только от крупного купечества и от биржевых комитетов. Между тем ни для кого не тайна, что в России интересы первой гильдии далеко не всегда совпадают с интересами второй гильдии [14, C. 40].

Одним из контраргументов Шершеневича против самостоятельного торгового судопроизводство является и то, что «русское общество слишком свыклось с новыми гражданскими судами, привыкло относиться к ним с полным уважением, и можно опасаться, что установление коммерческих судов все равно по французскому или германскому типу не только не вызовет симпатии среди общества и даже самого купечества, но скорее пробудит недоверие к этому учреждению» $[14$, с. 40].

Различных точек зрения придерживались и сами члены коммерческих судов. Так, в «Журнале Министерства Юстиции» был опубликован отзыв о преобразовании торговых судов председателя Архангельского коммерческого суда, товарища председателя и членов суда, которые заявляли, что «нет надобности в издании особого Устава торгового судопроизводства и в их (судов) сохранении на будущее время». При этом председатель суда г-н Михайлов заметил, что следует сократить сроки на подачу апелляций [2, с. 57].

Председатель и товарищ председателя Коммерческого суда Войска Донского писали, что «коммерческие суды пользовались до сего времени доверием торгового класса только потому, что общие суды были крайне неудовлетворительны, а ввиду превосходства нового Устава гражданского судопроизводства над Торговым уставом 1832 года должностные лица воскового коммерческого суда вполне соглашаются с мнением комиссии, что нет надобности в издании особого Устава торгового судопроизводства, что коммерческие суды отжили свой век $[2$, с. 58].

Такой же точки зрения придерживались председатель и члены Тифлисского коммерческого суда: «Вполне согласны с мнением комиссии, что нет надобности в дальнейшем сохранении торговых судов». При этом, однако, председатель предложил дополнить для практической пользы и устранения проволочек, принятые Комиссией правила в статьях 1310, 1336, 1346 и 1349 настоящего Устава коммерческого судопроизводства, в отношении окончательного решения торговых дел на определенную сумму в первой степени суда и в отношении начала торговых исков словесным заявлением [2, с. 58], что говорит о несовершенстве и нового торгового законодательства, готового сменить обособленное торговое судопроизводство. 
Небезынтересно мнение присяжного стряпчего того же суда г-на Дункель-Велинга. Соглашаясь с мнением комиссии о ненадобности издания особого Устава коммерческого судопроизводства, он полагает необходимым сохранение двух отвергнутых комиссией правил, которыми руководствовались коммерческие суды. А именно, «правила, оказывающиеся весьма полезными в коммерческой практике: во-первых, немедленное предъявление ответчику заявленного на него иска и, таким образом, его задержание и пресечение возможности скрыться от суда и от ответственности, а во-вторых, право заявлять иск не по месту жительства ответчика, а по месту его нахождения, то есть в месте совершения торговой сделки» [2, с. 58].

Так же присяжных стряпчий заявляет, разделяя мнение Комиссии об упразднении торговых судов относительно внутренних губерний России, что признает необходимым существование коммерческих судов для Закавказского края, а именно в Тифлисе. Свою точку зрения он обосновывает следующими «неудобствами». Во-первых, большинство торговых дел пришлось бы решать мировым судьям, которым в закавказском крае подсудны гражданские дела на сумму до 2 тысяч рублей, что «отняло бы у них много времени», между тем как им же поручены обязанности судебных следователей. Вовторых, при небольшом числе членов (6 человек) назначаемых в окружной суд в обязанности которых, кроме «прямых занятий по суду, будет лежать обязанность рассматривать апелляции, подаваемые на мировой суд. Такое положение вещей неминуемо приведет в накоплению дел и медленности в их решении, что особенно неудобно для торгового класса» [2, с. 59].

Таким образом, мнение присяжного стряпчего затрагивает основную цель торгового суда: скорость производства и динамичность решения экономических споров.

Неоднозначно мнение и председателя Бессарабского коммерческого суда. Разделяя мнение Комиссии о ненадобности издания особого Устава торгового судопроизводства, председатель суда, посредством критического разбора мнений французских юристов (Бонсена и Пьера Бравар-Вейериера), писавших о коммерческом судопроизводстве, пришел к заключению, что причин для сохранения торговых судов вообще нет, а в России в особенности. Но при этом замечал, что устанавливаемое Комиссией правило, что суд для разъяснения торговых обычаев может требовать «заключение сведущих людей», приведет «к медлительности производства» $[2$, с. 59].

Рассматривая данную проблему нельзя не упомянуть об однозначном мнении тех, для кого торговые суды были непосредственно учреждены - бессарабского купечества, которое «ввиду пользы приносимой коммер- ческими судами, полагает сохранить эти суды и после введения нового судопроизводства по крайней мере на два года, ввиду того, что в течении этого времени сама практика и опыт лучше всего решит возбужденные насчет коммерческих судов вопросы» [2].

Председатель Таганрогского коммерческого суда г-н Война также посчитал необходимым внести существенные поправки в решение Комиссии: допущение только сокращенного порядка производства и предоставление мировым судам решать споры только на сумму не выше 150 руб., ввиду того, что мировой судья «заваленный делами гражданскими и уголовными, не будет иметь возможности вести торговые дела с той поспешностью, как суд коммерческий». Г-н Война поднимает вопрос и о судьбе конкурсных дел (банкротство), ввиду того, что «по особому свойству этих дел и по их быстроте, с которой они должны разрешаться, в тех местностях, где существуют ныне коммерческие суды, уничтожение последних немыслимо без явного ущерба торговых интересов» $[2$, c. 60]. Члены Таганрогского коммерческого суда заявляют о том, что необходимо сохранить из Устава торгового судопроизводства все правила, имеющие влияние на производство, движение и решение экономических споров: назначение членов от купечества, сосредоточение специфических торговых дел в одном отделении суда и учреждение этих отделение во всех городах, в которых функционируют коммерческие суды, более того, принимая во внимание, что торговая практика во Франции доказала необходимость самостоятельного существования торговых судов, а в России таких учреждений очень мало и половина их содержания отнесена на счет городского финансирования, то «лучше бы было не упразднять данные суды, тем более, что при передаче дел в ведомство общих судов трудно будет согласовать подсудность по пространству действий этих судов с торговым районом, так как действие коммерческих судов распространяется не только на несколько уездов, но даже на несколько уездов [2, с. 61].

Рассматривая полемику о судьбе экономического правосудия, невозможно не обратиться к мнению одного из самых авторитетных юристов, сенатора, действительного тайного советника, участника проведения судебной реформы 1860-х гг., председателя С.-Петербургского коммерческого суда Александра Александровича Книрима. Разделяя, в целом, мнение Комиссии, А.А. Книрим предлагал внести ряд существенных, основополагающих изменений в Устав гражданского судопроизводства, которые как раз и составляли ядро торгового правосудия. Во-первых, для быстрого и правильного разрешения торговых дел, сохранить, помимо четырех дополнений к УГС, ряд постановлений действующего в то время УТС (ст. 1334, 1527, 1530, 1665, 1666 и 1692). Во-вторых, А.А. Книрим считал, что вопрос о дальнейшем существовании коммерческих судов сформулирован Комиссией неправильно, так как уничтожить коммерческие суды 
можно лишь в том случае, если практика обнаружила существенные в них недостатки, которые не могут быть изменены. Но на деле, заявлял председатель суда, ситуация прямо противоположная: дела решаются в коммерческих суда быстро и правильно. Это подтверждается тем, что в С.-Петербургском коммерческом суде между предъявлением иска и подписанием решения по существу проходит меньше времени, нежели в окружном суде, а с другой стороны, сравнением количества отмененных Сенатом с 1862-1864 гг. решений коммерческих судов с цифрой отмененных за этот же период решений гражданских палат и равных им судов 2-ой степени. Более того, торговое сословие, в интересах которого и учреждены коммерческие суды, довольно их деятельностью и испытывает к ним полное доверие. Так же в пользу коммерческих судов высказались и лица, служащие и служившие в этих судах.

А.А. Книрим резюмирует доводы, констатирующие адекватное функционирование торговых судов: приобретенное доверие торгового класса, правильное разрешение торговых дел не может быть достигнуто без участия лиц, профессионально занимающихся торговлей, следовательно, в состав коммерческих судов должны входить члены по выбору от купечества.

Председатель суда А.А. Книрим так же опровергает замечания Комиссии на вышеприведенные положения. Во-первых, Комиссия полагала, что коммерческие суды пользовались доверием торгового сословия только потому, что прежние суды были неудовлетворительны. На это Книрим возражает, что и в настоящее время петербургские купцы не изъявляли желания о передаче торговых дел во вновь открытые судебные места по той причине, что в делах, возникающих из торговых сделок, купечество всегда будет питать более доверие к суду, состоящему не только из юристов, но и из лиц торгового сословия [2, с. 62].

Говоря о самом существовании коммерческих судов, Книрим заметил, что торговые суды существуют не только во Франции и других государствах, в которых применяется Кодекс Наполеона, но и в Австрии, Баварии, Брауншвейге, Гамбурге, Бремени, Лейпциге и в Виртемберге, где торговые палаты действуют, как третейские суды для торговых дел. В Англии есть суды адмиралтейства для дел, вытекающих из мореплавания и банкротские дела о несостоятельности.

Таким образом, мнения сторонних юристов, членов коммерческих судов и представителей купечества разделились. После Судебной реформы был создан ряд комиссий, заключения которых были как идентичны, так и прямо противоположны. Несомненным преимуществом коммерческих судов являлась быстрота судопроизводства, его дешевизна и компетентность смешанного состава суда, включающего купеческий элемент. Полемика на страницах периодической печати второй половины XIX века в целом не дала положительных результатов: количество коммерческих судов в Российской империи сокращалось, но в основных торговых центрах страны, а именно в С.-Петербурге, в Москве и Варшаве, коммерческий суда продолжали успешно функционировать вплоть до 1917 года, когда Декретом о суде коммерческие суды были упразднены в связи с ликвидацией рынка и трансформацией социально-экономического строя страны.

\section{ЛИТЕРАТУРА}

1. Депп Н. Об особенностях торговых сделок // Журнал гражданского и торгового права. 1871. Кн.1. С. 1-45.

2. Журнал Министерства Юстиции. СПб.: Типография Правительствующего Сената, 1867. № 4, апрель. С. 59.

3. Журнал соединенных департаментов Законов и Гражданских дел Государственного совета о преобразовании судебной части в России. СПб. 1862. № 65.

4. Ольшанская Л.В. История возникновения и развития коммерческих судов в России // Известия МГТУ «МАМИ». Научный рецензируемый журнал. Серии «Экономика и управление» и «Социально экономические науки». М., МГТУ «МАМИ», 2014. № 1(19), т. 5. — С. 96-102.

5. ПСЗ - III. Т. Х. № 6931. 06 изменении порядка заочного разбирательства по гражданским делам и об обеспечении доказательств в местностях, где введено Положение о Земских Участковых начальниках.

6. ПСЗ-І. Т. ХХХ. № 22886. 10 марта 1808 года. Устав Коммерческого Суда для 0дессы. С. 115-124.

7. ПСЗ-І. Т. XXX. № 23018. Именной, данный Сенату. 06 учреждении Коммерческого суда в Таганроге от 12 мая 1808. С. 225.

8. ПСЗ-І. Т. XXXVI. № 27750. Именной, данный Сенату. 06 учреждении Коммерческого суда в Бессарабии от 1 апреля 1819. С. 130.

9. ПСЗ-І. Т. XXXVI. № 27957. Именной, данный Сенату. Об учреждении Коммерческого суда в Феодосии от 27 октября 1819. С. 363.

10.ПСЗ-І. Т. XXXVII. № 28109. Именной, данный Сенату. Об учреждении Коммерческого суда в Архангельске от 22 января 1820. С. 25.

11. ПСЗ-I. Т. VII. № 5360. 14 мая 1832 года. Высочайше утвержденное Учреждение Коммерческих Судов и Устав их судопроизводства. С. $268-298$.

12. Садовский В.С. Что делать с коммерческими судами? // Журнал гражданского и уголовного права. 1892. Кн. 7. С. 1-31.

13. Устав судопроизводства торгового. С разъяснениями / Сост.: Добровольский А.А. - С.-Пб.: Тип. т-ва «0бществ. польза», 1905. 374 с.

14. Шершеневич Г.Ф. Несколько слов о коммерческий судах // Журнал Министерства Юстиции. 1894-1895 гг. Книга 4. Февраль. С. 40-62.

() Ольшанская Людмила Владимировна (olshanskaya.miit@mail.ru).

Журнал «Современная наука: актуальные проблемы теории и практики» 